\title{
SINGLE POLYP OF THE LARGE INTESTINE IN CHILDHOOD
}

BY

\author{
J. R. HUGHES, R. T. JENKINS and D. E. STURDY \\ From the Department of Paediatrics, Morriston Hospital, Swansea
}

(RECEIVED FOR PUBLICATION NOVEMBER 25, 1955)

A single polyp of the large intestine is a well recognized entity. It is found in both children and adults and is to be differentiated from familial adenomatosis of the large intestine, which has been fully reviewed by Lockhart-Mummery and Dukes (1939).

The presenting symptom in most cases is rectal bleeding which may be of a chronic nature or may be severe. Other symptoms are prolapse of the polyp through the anal canal, intussusception or obstruction. The polyp may undergo malignant change.

\section{Case Report}

Janet H., aged 8, one of six children, was admitted to Morriston Hospital on July 27, 1955, with a history of severe bleeding per rectum and central colicky abdominal pain for 24 hours. She had been constipated for three days.

On admission, physical examination revealed no abnormalities. Digital examination confirmed the presence of red blood in the rectum. The father produced a specimen of a pint of bright red blood clot and mucus passed before admission. There was no history of rectal bleeding in other members of the family.

Blood was given intravenously. The patient suffered two further attacks of severe rectal bleeding and laparotomy was advised. The descending and pelvic colon contained blood. A small, nodular thickening in the pelvic colon was examined and excised after opening the bowel. No polypi were palpated in the large or small intestine. The patient made an uneventful recovery. Sigmoidoscopy and barium enema examinations later revealed no evidence of polypi.

On the night of admission the father produced a large polypoid mass, about the size of a walnut, which he retrieved from the pan used by the child at home (Fig. 1). Pathological section of the nodule removed at operation revealed normal colon mucosa. The section report on the polyp read: 'Adenomatous polyp made up of tall columnar mucus-secreting epithelium with well marked chronic inflammatory reaction. No sign of malignant change.' This polyp had amputated itself and the severe bleeding occurred from the mucosal end of the amputated stalk.

\section{Discussion}

How often does self-amputation occur? Numerous cases of rectal bleeding in infancy and childhood happen for no apparent reason. It is reasonable to suggest that in these cases a single adenomatous

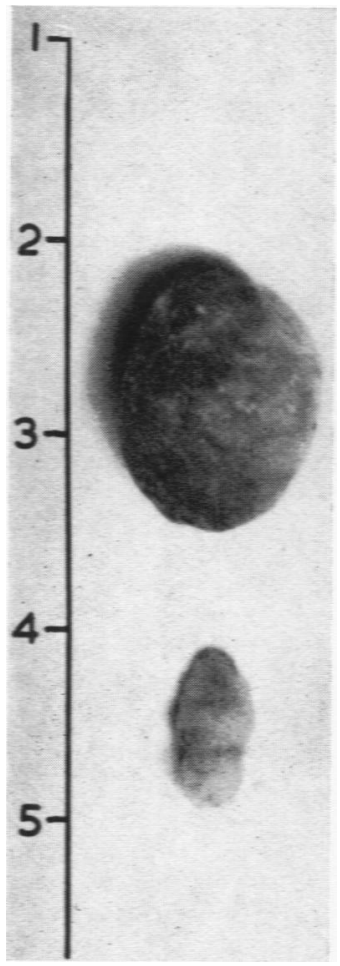

FiG. 1.-Photograph of the polyp extruded by the patient (scale in inches).

The smaller nodule was excised at operation.

polyp has amputated itself and that the extruded polyp has been lost.

The incidence of single or multiple polypi in children is unknown, but the figure generally quoted 
is about $3 \%$. In a series of 70 cases of rectal bleeding in children under 6 years of age investigated by Harris (1953), 48 had polypi in the rectum, 16 in the sigmoid and six above the sigmoid colon: 52 were single polypi only. In eight cases there was self-amputation of the polyp, an incidence of $11.4 \%$ and four of these were brought to the surgery by parents. He comments that the number of cases that get well by self-amputation seems remarkable. In another series of 349 cases, reported by Kerr (1948), 100 had polypi, of which 68 had a single polyp only. He states that 'frequently a single episode of severe melaena may be evidence of selfamputation of a polyp (18 cases) and the tumour may be produced by an intelligent parent. The incidence of self-amputation in this series was $18 \%$.
Kerr states that self-amputation is frequent in children, but rare in adults.

\section{Summary}

A case of self-amputation of a single polyp of the large intestine is reported. The incidence of the polypi is about $3 \%$. Malignant change may occur. It seems very likely that many cases of rectal bleeding in infancy and childhood follow selfamputation and extrusion of a polyp of the large intestine. The chance of this occurring is not established; the two figures quoted place it at $11.4 \%$ and $18 \%$.

\section{REFERENCES}

Harris, J. W. (1953). Amer. J. Surg., 86, 577

Kerr, J. G. (1948). Ibid., 76, 667.

Lockhart-Mummery, J. P. and Dukes, C. E. (1939). Lancet, 2. 586. 